\title{
A pandemia, o ideal e o material ${ }^{1}$
}

\author{
The pandemic, the ideal and the material
}

\section{Laurenio Leite Sombra ${ }^{1}$}

1 Doutor em Filosofia (2015) pela Universidade Federal da Bahia (UFBA) e Mestre em filosofia pela Universidade de Brasília (Unb). É o editor da Revista Ideação (UEFS). Professor Adjunto da Universidade Estadual de Feira de Santana (UEFS).

E-mail: lausombra@hotmail.com Orcid: http://orcid.org/0000-0002-2998-6059

RESUMO: Este artigo visa investigar a imbricação entre ideal e material a partir de formulação do antropólogo francês Maurice Godelier, em diálogo com Marx. O problema formulado é: dado o contexto da pandemia mundial da Covid-19, com ênfase na especificidade brasileira, como pensar os problemas que vivemos atravessados pelas "realidades ideais" (termo de Godelier) forjadas no capitalismo e, mais especificamente, no capitalismo brasileiro? O objetivo é formular algumas proposições conceituais que, articuladas, definam a própria condição central do capitalismo, referidas posteriormente ao caso atual. A investigação é de natureza filosófica, pensada, no sentido de Frédéric Cossutta, como "reexame e definição do conceito", tendo como "referência" (ainda no sentido de Cossutta) a própria pandemia. Os resultados apresentados mostram que as "idealidades" principais atribuídas ao capitalismo - o individualismo, o nacionalismo, a primazia do dinheiro, o ideal de multiplicação permanente do valor e um modo particular e dinâmico de perfazer divisões de grupos sociais - operam conjuntamente nas reações apresentadas, nas exigências de "volta à normalidade" e nas desigualdades a elas associadas. O artigo conclui com uma reflexão inicial sobre os desafios para a reversão de um quadro dessa ordem, rejeitando formulações idealistas - como certa ideia de "conscientização" eventualmente sugere -, mas também formulações mecanicamente materialistas - como pode sugerir certo modelo de revolução a partir de um ato "acima da sociedade".

Palavras-chave: Godelier, marxismo, Covid-19.

ABSTRACT: This paper aims to investigate the interweaving relation between the ideal and the material based on the formulation of the French anthropologist Maurice Godelier, in dialogue with Marx. The problem formulated is: given the context of the world pandemic of Covid-19, with an emphasis on Brazilian specificity, how should we think about the problems we live in entangled by the "ideal realities" (Godelier's term) forged in capitalism and, more specifically, in Brazilian capitalism? The objective is formulating some conceptual propositions that, articulated, define the very central condition of capitalism, extending it later to the current case. The investigation is of a philosophical nature, conceived, in the sense of Frédéric Cossutta, as "review and definition of the concept", having the pandemic as its "reference" (still in the sense of Cossutta). The results presented show that the main "idealities" attributed to capitalism - individualism, nationalism, the primacy of money, the ideal of permanent multiplication of value, and a particular and dynamic way of making up divisions of social groups - operate together in the reactions presented, in the demands of "return to normality" and in the inequalities associated with them. The article concludes with an initial reflection on the challenges for the reversal of a picture of that order, rejecting idealistic formulations - as certain idea of "search for awareness" eventually suggests -, but also mechanically materialistic formulations - as a certain model of revolution driven by a group "above society".

1 Um esboço ainda inicial dessa noção foi publicado na "Coluna ANPOF" em março de 2020. http://anpof.org/portal/index.php/en/comunidade/coluna-anpof/2517-coronavirus-e-o-retorno-a-ontologia 
Keywords: Godelir, Marxism, Covid-19.

\section{Introdução}

O acontecimento da pandemia mundial ocasionada pela Covid-19 nos impõe reflexões de diversas ordens, além das imediatas discussões médicas e sanitárias. Estas reflexões abordam tanto causas dos fenômenos, quanto seus possíveis desdobramentos, incluindo discussões ético-políticas acerca do que faz̧er diante desse quadro. Talvez possamos dizer que elas não tragam em si grande novidade conceitual. Em geral se aborda questões que já estavam postas, como a destruição progressiva do nosso habitat natural, com óbvios desdobramentos ecológicos; a nossa ampla integração mundial, agora ameaçada; a dependência de crescimento no modo de produção capitalista; e a nossa profunda desigualdade social.

O que mudou, aparentemente, foi o sentido de urgência dessas reflexões. Em diversos momentos, certa temporalidade aparentemente estendida dos problemas apontados ou certa sensação de que eles estavam muito distantes de nós facilitavam o seu diferimento. Agora, não, a pandemia atravessa todas as conversas, todos os noticiários, as discussões nas redes sociais, o nosso cotidiano. O possível colapso do sistema de saúde, o medo da morte, o isolamento social, a violência doméstica, a depressão econômica inevitável, os riscos de desemprego, as discussões sobre serviços "essenciais", a situação política do país, todos esses e outros elementos conjugam reflexões mais amplas e que já não parecem poder esperar. Somos afetados de um modo diferente pelas mesmas questões que já estavam postas, mas chegavam com dificuldade no nosso mundo cotidiano. É nesse contexto novo que nos propomos a pensar.

Esta investigação será de ordem filosófica, no sentido de Frédéric Cossutta (1994, p. 40), que defende o texto filosófico como "reexame e definição do conceito" e no qual "unidades de sentido são fixadas, ligadas, hierarquizadas para constituir um universo autônomo de significação"; ao mesmo tempo que dialoga com uma referência, um "elemento extralinguístico manifestado através do exemplo e do caso particular" (1994, p. 44). Essa articulação do conceito com a referência é que permite o desdobrar da filosofia na sua relação com o cotidiano, o "real". Assim, segundo Cossutta (1994, p. 50-51), "o conceito filosófico apresenta-se como um operador textual que, graças às propriedades da língua, permite categorizar o real ou o ser integrando-os no mundo do dizível".

No nosso caso, a referência imediata à qual nos atemos é a pandemia e, com ela, os diversos desdobramentos sociais, presentes e instalados no campo do possível, que ela acarreta. A discussão conceitual proposta, por sua vez, se dá em diálogo com o pensamento marxista ${ }^{2}$, estimulado por uma abordagem particular dele: a formulação do antropólogo Maurice Godelier, para quem as sociedades humanas podem ser melhor compreendidas numa articulação complexa de "ideal" e material. Nestes termos, embora a "base material" reivindicada pelo pensamento marxista seja fundamental, é preciso compreendê-la em interação constante e dialética com a construção humana de "ideais". O que significa pensar esta articulação? De que modo ela pode contribuir para revelar alguns aspectos fundamentais do fenômeno que vivemos hoje? Como pode, ao mesmo tempo, saindo da urgência da pandemia, revelar crises mais longas e aparentemente menos urgentes, como a crise econômica e planetária? São questões como essas que se tenta ao menos esboçar aqui.

\section{O marxismo, o material e o ideal}

Marx desenvolveu, ao longo da sua obra, uma formulação filosófica que reivindicava como elemento

\footnotetext{
20 que se nomeia aqui como "pensamento marxista" será melhor explicado em seguida.
} 
central da compreensão dos processos históricos e sociais da humanidade a investigação das suas "bases materiais". Estas bases estão diretamente associadas ao que ele chamou com Engels, na Ideologia alemã (1998, p. 35), de "produção material da vida imediata". Afinal de contas, como eles afirmam (1998, p. 21), "para viver é preciso antes de tudo beber, comer, morar, vestir-se e algumas outras coisas mais". Estes são, pois, os elementos "materiais da vida imediata" que nos afligem antes de tudo e que não podem ser descurados no bojo da ação humana.

É a partir dos desafios e das soluções encontradas pelos agrupamentos humanos em torno dessas bases materiais que se dão as organizações sociais; e, com elas, as diversas camadas, por mais sofisticadas que sejam, de atuação da humanidade - filosofia, ciência, arte, religião, direito, política. A primeira grande contribuição de Marx ${ }^{3}$, nesse sentido, foi compreender esses fenômenos em uma espécie de "totalidade", tendo como eixo condutor o constante desafio da humanidade em torno da produção de um mundo que atenda às suas necessidades, desde as mais elementares. De novo podemos citar a mesma obra assinada por Marx e Engels (1998, p. 35-36).

Essa concepção da história (...) concebe a forma dos intercâmbios humanos ligada a esse modo de produção e por ele engendrada, isto é, a sociedade civil em seus diferentes estágios, como sendo o fundamento de toda a história, o que significa representa-la em sua ação enquanto Estado, bem como em explicar por ela o conjunto das diversas produções teóricas e das formas da consciência, religião, filosofia, moral etc., e a seguir sua gênese a partir dessas produções, o que permite então naturalmente representar a coisa em sua totalidade (e examinar também a ação recíproca de seus diversos aspectos). Ela (...) explica a formação das ideias segundo a prática material.

Podemos dizer que uma formulação como a descrita acima, naturalmente com os diversos desdobramentos teóricos que recebeu posteriormente, é a base do que podemos chamar de "marxismo" ou "pensamento marxista". A vinculação dos fenômenos humanos a uma base material obstrui uma série de formulações tipicamente "idealistas", que tentam compreender fenômenos estéticos, morais, sociais, psicológicos, ambientais, políticos e mesmo filosóficos em completa desassociação com essa estrutura abrangente e concreta da história humana. E abre todo um leque de investigações "marxistas" em diversas áreas de pesquisa e de militância política. Nesse sentido, o termo marxismo pode ser vinculado ao conjunto de práticas e investigações que decorreram das possibilidades abertas por um pensamento que possibilitava outro modo de agir, de fazer ciência e fazer filosofia, que articulava o seu objeto de investigação às atividades materiais e concretas. Não se refere ou não deve se referir, portanto, a uma aceitação tácita das ideias de Marx, por diversas vezes criticadas por pensadores marxistas em alguns dos seus aspectos.

Mas o que significa filosoficamente essa primazia dos modos de produção, para além do fato de que precisamos atender às nossas necessidades essenciais? Como se chega a ela, e que implicações isso traz? Esta pergunta impõe alguns desafios porque Marx não deixou, em vida, obras publicadas que desenvolvessem, em toda a sua extensão, as bases ontológicas da sua formulação, embora as pinçasse em trechos de seus trabalhos, como no início do capítulo V de O Capital, no prefácio da Crítica da economia política, entre outras. Textos não publicados, encontrados posteriormente, como Os Manuscritos econômico-filosóficos de 1844, a própria Ideologia alemã as Teses sobre Feuerbach e os Grundrisse colaboraram em grande medida para completar esse quadro. A partir daí, diversos filósofos marxistas empreenderam o desafio de desenvolver e aprofundar estes fundamentos. Entre eles, o pensador húngaro György Lukács, que formulou no final da sua vida a grande obra Para uma ontologia do ser social, na qual tentava desenvolver os fundamentos ontológicos da construção

${ }^{3}$ Antes ainda de sua explicação filosófica sobre o capitalismo, como se discutirá posteriormente. 
marxiana, mostrando que a obra de Marx parte acima de tudo de uma ontologia do ser social, isto é, de uma constituição basilar de realidade que se inscreve na relação com a natureza, mas que se transforma, pela mediação humana, constituindo nela outro estágio de realidade objetiva.

Para tanto, é fundamental compreender as bases complexas da relação humano-natureza, frequentemente segmentada na filosofia e nas ciências. Essa percepção já estava clara nos Manuscritos do jovem Marx em 1844. Lá, ele já dizia (2010, p. 84):

o homem vive da natureza significa: a natureza é o seu corpo, com o qual ele tem de ficar num processo contínuo até morrer. Que a vida física e mental do homem está interconectada com a natureza não tem outro sentido senão que a natureza está interconectada consigo mesma, pois o homem é uma parte da natureza.

Mas essa relação com a natureza, ou mesmo essa condição de ser natureza, é peculiar na humanidade. Nos mesmos Manuscritos, Marx acrescenta (2010, p. 128):

o homem não é apenas ser natural, mas ser natural bumano, (...) que enquanto tal tem de atuar e confirmarse tanto em seu ser quanto em seu saber. (...) A natureza não está nem objetiva nem subjetivamente imediatamente disponível ao ser humano de modo adequado.

Estas são passagens fundamentais para a compreensão ontológica que esse jovem pensador começava a formular. Em certo sentido, ao mesmo tempo que somos natureza e precisamos lidar constantemente com a natureza, só confirmamos nosso mundo na nossa ação mesma de transformação, ele não está dado ou "imediatamente disponível". Essa é a base do próprio conceito de práxis que Marx esboça pouco depois, nas suas Teses sobre Feuerbach. A ação humana só se realiza enquanto ação transformadora que, ao mesmo tempo, lida com um mundo prático a transformar. Só nessa relação de um sujeito ativo social que transforma a realidade objetiva, transformando-se e produzindo outra realidade objetiva, é que se inscreve a própria realidade humana. "É na práxis que o homem precisa provar a verdade, isto é, a realidade e a força, a terrenalidade do seu pensamento" (MARX, 1998, p. 100).

Esta concepção em Marx cada vez mais vai se materializar a partir do conceito de trabalho como categoria central, mas isso não significa em absoluto o abandono das formulações centrais em torno da práxis $^{5}$. É a mesma condição de sujeito transformador ativo das Teses sobre Feuerbach que aparece no cap. V de O Capital, quando Marx afirma (1996, p. 297-298):

antes de tudo, o trabalho é um processo entre o homem e a Natureza, um processo em que o homem, por sua própria ação, media, regula e controla seu metabolismo com a Natureza. (...) Ao atuar, por meio desse movimento, sobre a Natureza externa a ele e ao modifica-la, ele modifica, ao mesmo tempo, sua própria natureza. (...) No fim do processo de trabalho obtém-se um resultado que já no início deste existiu na imaginação do trabalhador, e portanto idealmente. (...) Além do esforço dos órgãos que trabalham, é exigida a vontade orientada a um fim, que se manifesta como atenção durante todo o tempo de trabalho.

\footnotetext{
${ }^{4}$ Esse sujeito transformador de Marx não é um indivíduo isolado. Nas Teses sobre Feuerbach, ele também afirma (1998, 101): "a essência do homem não é uma abstração inerente ao indivíduo isolado. Na sua realidade, ela é o conjunto das relações sociais".

5 Pensados como atividade transformadora, até certo ponto práxis e trabalho são termos intercambiáveis no momento dessa formulação ontológica inicial, muito embora com desdobramentos semânticos diferenciados - que não caberiam desenvolver ou problematizar nesse artigo.
} 
Para Lukács, interpretando Marx, é justamente essa condição intermediária, de lida concreta com o mundo natural e ao mesmo tempo de construção de idealidades, que faz do trabalho a categoria fundamental de transição para uma ontologia do ser social. Para o filósofo húngaro (2013, p. 44), "no trabalho estão contidas in nuce todas as determinações que (...) constituem a essência do novo ser social". A partir dele, são constituídos novos mundos que forjam novas realidades objetivas tão concretas quanto as realidades do mundo natural, sujeitas igualmente, em diversas situações, às relações de causa e efeito que as caracterizam; mas, ao mesmo tempo, inscreve-se uma dimensão de liberdade que lhe é peculiar, no sentido de que possibilidades alternativas podem ser desenvolvidas no bojo da própria experiência humana. Não uma liberdade abstrata, visto que sempre fundada nas objetividades em que ela mesma se inscreve e, em última instância, na própria natureza que não deixa de a constituir; muito menos uma mera liberdade individual, segundo o modelo liberal, porque é uma liberdade constituída socialmente. Mas, ainda assim, uma liberdade fundamental, centro da aventura humana.

É nesse âmbito, aqui se defende, que é possível inscrever a formulação do antropólogo marxista Maurice Godelier. Para ele, essa fundamentação ontológica marxiana deve ser compreendida numa articulação profunda entre material e ideal. Godelier resgata a palavra francesa pouco usada cotidianamente, idéeel, mais associada a certa construção filosófica de idealidades, para diferenciá-la do termo mais cotidiano idéal, que remeteria a algo imaginário, que se contrapõe ao concreto. Segundo o próprio Godelier (1989, p. 157)

Toda relação social, qualquer que seja, inclui uma parte ideal [idéel], parte de pensamento, de representações; estas representações não são unicamente a forma que reveste essa relação para a consciência, mas formam parte de seu conteúdo. É necessário não confundir ideal [idée] com ideal [idéale] ou imaginário.

Esta conjugação indissociável forma o que ele chama de "realidades ideais", num oxímoro que ajuda a constituir conceitualmente o que não pode ser pensado separadamente. Assim como em Marx, esta formulação não supõe uma "concessão idealista" ao materialismo, mas a constatação concreta de que a condição humana pressupõe uma articulação significativa das ações práticas, de modo que as conjure simbolicamente, para que sejam narradas, compartilhadas e representadas, que façam sentido para as comunidades que delas participam.

As distintas realidades ideais que se encontram no seio de um processo laboral podem ser classificadas em dois grandes tipos, segundo as funções que assumam as representações. De um lado, as representações e os princípios que, enquanto interpretação do real, pretendem organizar as formas adotadas pelas distintas atividades materiais (processo de trabalho), e as fases de seu desenvolvimento são as taxonomias de plantas, de animais, de solos, de fenômenos climáticos, de regras de fabricação e de uso de ferramentas, de esquemas de ações materiais e de condutas simbólicas. Por outro lado, as representações que explicam por que tal ou qual tarefa deve ser reservada aos homens, às mulheres, aos jovens, aos escravos, às pessoas comuns, aos mestres, aos aristocratas, ao rei...; em suma, as representações que legitimam o lugar e o status dos indivíduos e dos grupos frente às realidades, que são permitidas, proibidas, impostas etc. (GODELIER, 1989, p. 160-161).

Se observarmos, todas as distinções estabelecidas exigem "realidades ideais", representações simbólicas que permitam que elas sejam efetivadas. Dizendo de outro modo e em outra perspectiva, há sempre signos que conjugam abstração e efetividade prática nas realidades sociais (SOMBRA, 2019).

6 Muitas das formulações de Godelier têm consonância com formulação teórica que desenvolvi desde 2015, sob o nome de rede de sentidos, ainda mais especialmente quando os signos que a constituem têm papel fundamental na própria constituição dos sujeitos (SOMBRA, 2015). 
O que se quer ressaltar aqui é que essas "realidades ideais" estão no centro da ontologia do ser social, não são mera decorrência dela. A própria emergência do ser social na construção de objetividades a partir de uma relação metabólica com a natureza só é possível porque o ser humano interage essa relação metabólica com a relação simbólica que a dá sentido e potência diferenciada. É isso que permite que se desenvolva um trabalho que antes "existiu na imaginação do trabalhador", como afirmou Marx. E é isso que permite que grupos sociais definam quem desenvolverá esse trabalho, quem será "proprietário" dos meios que permitam desenvolvê-lo e quem ficará com os seus frutos. Godelier afirma (1989, p. 183) que "representar, organizar, legitimar são outras tantas maneiras de produzir sentido". Ora, a atribuição de sentido dá direção a uma prática, a organiza, a legitima. Não a nega, ao contrário, a possibilita. É nesse contexto que são necessárias as "realidades ideais", que doravante nomearemos como idealidades.

Com essa base ontológica assentada, é possível compreender de maneira mais profunda a primazia marxiana dos modos de produção. Um dos textos mais discutidos e questionados a esse respeito foi o prefácio da Contribuição à crítica da Economia Política, em que Marx afirma (2008, p. 47): “o modo de produção da vida material condiciona o processo de vida social, política e intelectual. Não é a consciência dos homens que determina o seu ser; ao contrário, é o ser social que determina sua consciência”. No mesmo parágrafo em que fala desse embasamento na vida material, que se solidifica nas relações de produção, Marx fala que sobre ele "se eleva uma superestrutura jurídica e política e à qual correspondem formas determinadas de consciência" (Idem, p. 47).

Com essa contraposição entre modos de produção (as "bases materiais") e relações jurídicas, políticas e ideológicas, estava criada a famosa metáfora base-superestrutura. Metáfora muitas vezes discutida e também muitas vezes criticada, mesmo por alguns autores marxistas, como o historiador inglês Edward Thompson, que entende que ela (1999, p. 256) "está dotada de uma inerente tendência ao reducionismo ou ao determinismo vulgar, classificando atividades e atributos humanos ao dispor alguns destes na superestrutura (...), outros na base (...) e deixando outros a flanar, desgraçadamente no meio".

De fato, resgatados os fundamentos ontológicos do próprio Marx, a metáfora deve no mínimo ganhar alguns matizes mais complexos. Se as "bases materiais" articulam de modo inexorável a relação metabólica com a natureza e a construção humana de idealidades, a constituição social histórica que representa um modo de produção também já contém em si essa articulação, não se podendo, nesse sentido, remeter necessariamente as estruturas jurídicas, políticas e ideológicas a meras derivações. O que torna o olhar sobre essas estruturas um olhar "marxista" é que elas não podem ser compreendidas sem a perspectiva de que são constituídas, primordialmente, em torno do desafio concreto da humanidade em sua lida com a natureza, mediado pelo trabalho, do desafio da produção e da reprodução. É nesse sentido que o próprio Thompson resgata outra metáfora de Marx, provavelmente mais pertinente e curiosamente menos famosa, estabelecida nos Grundrisse. Lá ele afirma que cada forma de produção e suas relações de produção (2011, p. 59) "estabelecem a posição e a influência das demais produções e suas respectivas relações", completando: "é uma iluminação universal em que todas as demais cores estão imersas e que as modifica em sua particularidade. É um éter particular que determina o peso específico de toda existência que nele se manifesta". Se nos basearmos nessa outra metáfora, compreendemos que as diversas formas sociais, relações políticas, jurídicas, religiosas, ideológicas, entre outras, não são meras derivações, mas são "iluminadas" e têm seu "peso específico" melhor compreendido pelos modos de produção, e é justamente esta articulação que dá sentido de totalidade à investigação marxista.

Esta compreensão, algo mais complexa, dos modos de produção e das “idealidades” a eles associadas ganha plena materialidade nas relações [sociais] de produção. O termo relações de produção [Produktionsverhältnis- 
se] em Marx é referido, em geral, ao modo sistêmico ou estrutural com o qual são constituídas divisões em uma determinada comunidade/sociedade, concedendo a cada grupo acesso diferenciado aos recursos, à organização do processo de trabalho e aos seus próprios resultados. Em um sentido amplo do termo, as relações de produção regimentam sobre a propriedade desses grupos sociais, desde que "propriedade" seja pensada aqui para além de uma definição meramente formal, e inclua modos variados de concessão a práticas humanas ${ }^{7}$ Como afirma Gerald Cohen (1986, p. 38), "dado que as relações de produção constituem a estrutura econômica de uma sociedade, esta estrutura está determinada pela distribuição nela dos direitos (efetivos) de propriedade sobre as pessoas e as forças produtivas".

Embora o termo mais genérico adotado por Marx para falar nessas divisões tenha sido "classe" [Klasse], ele não limitou-se a ele ao falar na "divisão do trabalho dentro da sociedade", reconhecendo mesmo em O Capital que muitas comunidades partiam de outras divisões, separando os grupos sociais por família, por tribo, por idade e por sexo (MARX, 1996, p. 466-467). Estas divisões podem, até certo ponto, incorporar componentes "naturais" , mas estes componentes são em larga medida insuficientes para explica-las. Aqui, são fundamentais as idealidades que forjam diferenciações religiosas, de gênero, de classe, de raça, étnicas, de casta, de nacionalidade ou de faixa etária. Junto com estas divisões, constitui-se todo um aparato, ao mesmo tempo simbólico e prático, que define de modo mais ou menos explícito a quem cabe o que, quem poderá fazer o que, quem detém direitos sobre o que, quem fica com os frutos do que se produz. Isso forja um amplo leque de regras (implícitas ou explícitas) que pode reger desde quem tem acesso a práticas rituais, passando pelo acesso à produção e divulgação do conhecimento, à participação política, às benesses e proteções do Estado, até à definição de quem é o proprietário (e principal beneficiário) dos meios de produção. Resgatando o que já foi citado de Godelier, estas idealidades forjam

as representações que explicam por que tal ou qual tarefa deve ser reservada aos homens, às mulheres, aos jovens, aos escravos, às pessoas comuns, aos mestres, aos aristocratas, ao rei...; em suma, as representações que legitimam o lugar e o status dos indivíduos e dos grupos frente às realidades, que são permitidas, proibidas, impostas etc. (GODELIER, 1989, p. 161).

Aqui estão, portanto, alguns elementos que estruturam a ontologia do ser social numa interação indissociável entre o material e o ideal, as “idealidades” que enformam o material. Se esta formulação faz sentido e, mais do que isso, for central para a compreensão dos fenômenos sociais, a reflexão acerca da pandemia ocasionada pela Covid-19 pode ser iluminada por ela, em alguma medida. Para isso, no entanto, é necessário localizá-la no contexto histórico em que vivemos. Aqui, o elemento mais concreto da reflexão iniciada por Marx, acerca da primazia do capital, se faz necessário.

\section{O modo de produção capitalista}

Se tentamos pensar a pandemia à luz dos princípios ontológicos acima delineados, temos que estabelecer uma mediação fundamental que a torna mais concreta: ela se dá em um contexto histórico

\footnotetext{
7 Godelier define propriedade como (1989, p. 100) "um conjunto de regras abstratas que determinam o acesso, o controle, o uso, a transferência e a transmissão de qualquer realidade social que possa ser objeto de discussão. (...) Formalmente falando, o conceito de propriedade é aplicável a qualquer realidade tangível ou intangível: a terra, a água, uma máscara, os conhecimentos rituais, as fórmulas mágicas secretas que asseguram a fertilidade das plantas ou das mulheres, uma classificação [un rango], o nome dos mortos etc.".

8 Idosos já sem energia para determinadas atividades, crianças ainda não preparadas para elas, mulheres sem a mesma força física etc.
} 
determinado, a saber, o da hegemonia do modo de produção capitalista na primeira metade do século XXI. No nosso caso, com uma delimitação socioespacial e também histórica específica em sua manifestação no Brasil. Que aspectos conceituais podem contribuir para compreender esse contexto?

A princípio, precisamos constatar algo óbvio: as sociedades, inclusive a brasileira, estão produð̨indo coisas e/ou transacionando com outras que também produzem; e consumindo essas coisas: alimentos, meios de transportes, roupas, abrigos, objetos de entretenimentos, medicamentos, mas também serviços, inclusive serviços de saúde. São sociedades feitas de seres humanos de carne e osso que têm desejos e necessidades, inclusive biológicas, que sentem prazer, dor, emoções favoráveis e desfavoráveis, se relacionam mutuamente, e para satisfazer as suas necessidades têm que lidar (metabolicamente) com o mundo natural que os rodeiam e os constituem: seu próprio corpo, as diversas fontes de alimentação e de energia, os animais, as plantas, as vegetações, o planeta. E que lidam com o que há de favorável nesse contexto, mas também com o que há de hostil nele: a degradação do solo, os ventos e tempestades, o adoecimento do próprio corpo, os vírus e as bactérias.

Essa é a "base material" incontestável das nossas relações. Elas, no entanto, são particularizadas historicamente quando inscritas no modo de produção capitalista. O que o caracteriza? Se seguirmos a definição de Immanuel Wallerstein (2001, p. 13-15), o seu elemento fundamental, o capital, se dá como "riqueza acumulada", como uma organização social na qual toda uma cadeia é articulada de modo que haja produção sistemática, disponibilidade de crédito e de trabalhadores, sistema de distribuição, opção de comercialização, enfim todo o circuito seja organizado para que o valor produzido nessa cadeia seja permanentemente acumulado e multiplicado. Como Marx afirmou em O Capital (1996, p. 272), "o fim de cada ciclo individual (...) constitui (...), por si mesmo, o início do novo ciclo (...). Por isso, o movimento do capital é insaciável”. Para que esse circuito "insaciável” seja possível, do ponto de vista material, vários fatores são necessários: uma produtividade incessante e cada vez mais intensificada, descoberta permanente de nova fontes de energia junto com um aproveitamento eficiente das fontes existentes, logística necessária para circulação dos produtos desenvolvidos, descoberta permanente de novos mercados e/ou intensificação dos mercados já existentes.

Mas quais são as "idealidades" associadas a esse circuito e que dão forma a ele, permitindo que ele aconteça e se reproduza? Naturalmente, não seria possível num curto espaço abordá-las com toda a sua dignidade, mas alguns aspectos podem ser aventados: seguindo a formulação de Godelier, é necessário um conjunto de representações que deem sentido a esse processo insaciável de multiplicação, que tornem "natural" o seu ciclo. Aqui, tentaremos esboçar alguns aspectos fundamentais que compõem essas idealidades.

Um primeiro aspecto: no modo de produção capitalista é necessário solapar a primazia de configurações comunitárias, visto que nestas configurações as transações de coisas ou serviços produzidos não se fazem prioritariamente tendo em vista uma maximização de ganhos, mas uma relação de reciprocidade, para usar a noção desenvolvida por Dominque Temple (1995). A reciprocidade é uma relação que só se torna possível porque os membros de determinada comunidade se sentem parte do mesmo elo, conjugados de algum modo. Movidos por esse elo, eles transacionam os bens produzidos sob uma ótica não mercantil, com obrigações igualmente importantes (e não medidas quantitativamente) de dar, receber e devolver, o que Marcel Mauss (1974) nomeou como dávida/dom [don]. Nestas relações, o que cabe a cada um é percebido como devido ao próprio elo comunitário: "cada uma destas obrigações cria um laço de almas entre os atores do dom. [O ato de] dar instaura uma aliança, um laço espiritual, uma comunhão, mas receber (e também tomar) permite igualmente unir o outro a si” (TEMPLE, 2003, p. 25).

Ao estudar as relações de reciprocidade, Temple faz uma observação curiosa (1995, p. 92): os povos 
que ele estudou (os ameríndios) não desconheciam trocas mercantis, mas só as realizavam justamente com outros povos com os quais não havia vínculos mútuos, quando a própria condição de humanidade (e nela, de compartilhamento de um sentido comum) era fragilizada, em certa relação com escravos, estrangeiros, párias. Justamente uma relação que não unia os indivíduos que dela faziam parte num elo comunitário. Esta constatação é fundamental porque a constituição do individualismo, idealidade necessária ao capitalismo, exigiu justamente o rompimento desses elos. Mesmo que esse rompimento nunca tenha sido absoluto, visto que sempre contraposto precariamente por ligações coletivas de ordem religiosa, nacional, partidária ou de algum tipo complementar de agremiação, elas nunca impediram a fragmentação basilar das relações de reciprocidade típicas do individualismo, como se, em certa medida, todos se tornassem estrangeiros uns dos outros. Essa fragmentação foi fundamental para que os indivíduos assumissem, no lugar, a lógica competitiva das relações mercantis. Sem conhecer tais investigações antropológicas, Marx (1996, p. 212) intuiu essa dependência com clareza:

As coisas são, em si e para si, externas ao homem e, portanto, alienáveis. Para que a alienação seja recíproca, basta que os homens se defrontem, tacitamente, como proprietários privados daquelas coisas alienáveis e portanto, por intermédio disso, como pessoas independentes entre si. (...). A troca de mercadorias começa onde as comunidades terminam, em seus pontos de contato com outras comunidades ou com membros de outras comunidades. Tão logo as coisas se tornam mercadorias no exterior da comunidade, tornam-se também por repercussão mercadorias no interior da vida comunal. (...) A partir desse momento, consolida-se, por um lado, a separação entre a utilidade das coisas para as necessidades imediatas e sua utilidade para a troca.

Esse rompimento dos elos comunitários em prol do individualismo teve como contraponto crescente outra idealidade, o nacionalismo e a própria ideia da constituição de cidadãos como um conjunto de indivíduos que pertencem "contratualmente" a um Estado-nação. No entanto, esta não é uma conformação que restitui os valores recíprocos inerentes a uma comunidade, embora crie os requisitos mínimos de pertinência. Como afirma Luís Villoro (1998, p. 29-30):

Ao desintegrar-se as comunidades históricas (...) os indivíduos começam a deixar de reconhecer-se nas culturas locais; se desprenderam de sua terra, perderam seu solo. (...) Então têm de inventar-se uma associação mais ampla. (...) Substituem assim as comunidades vividas por outra inventada. (...) Este é o novo Estado-nação.

Assim, é nesse contexto de indivíduos fragmentados, mas pertencentes a um Estado-nação, que se dão as relações mercantis. No lugar das relações de reciprocidade, a troca mercantil enraíza-se num fundamento cada vez mais quantitativo - base do valor de troca (MARX, 1996). É preciso que as trocas mercantis se tornem mensuráveis, já que não há a fluidez qualitativa das relações comunitárias que contam com um elo invisível para legitimar a justiça das ações recíprocas realizadas. E esse fundamento quantitativo se consolida de modo cada vez mais abstrato na forma do dinheiro - base suprema de valor nas relações capitalistas. A primazia do dinheiro, assim, torna-se também uma idealidade fundamental a orientar boa parte das relações. Como toda idealidade, no sentido trazido por Godelier, totalmente incrustada numa materialidade, os próprios modos de produção, em uma relação dialética indissociável. A primazia do dinheiro torna indiferente as formas qualitativas de valor produzidas, tornando, no linguajar de Marx, o valor de uso subordinado ao valor de troca das mercadorias (MARX, 1996), direcionando o mundo social para as formas de produção que mais favoreçam quantitativamente ao seu ganho.

A primazia do dinheiro como valor fundamental dentre as idealidades do sistema capitalista remete 
a outro aspecto essencial, também sinalizado por Marx, e que praticamente define o sistema capitalista: a lógica de acumulação de capital como mecanismo de multiplicação permanente do valor. Marx diz isso de forma muito clara quando insere o conceito de mais-valia em $O$ Capital, e mostra, nesse contexto, um movimento “insaciável”, como já se disse, e no qual a meta subjetiva do capitalista é (1996, p. 273) a "apropriação crescente da riqueza abstrata" num "incessante movimento do ganho". Acrescentaríamos: mais do que uma meta subjetiva do capitalista, todo o sistema social se move nessa direção, a idealidade da multiplicação permanente do valor torna-se mola propulsora de uma sistemática que visa constante inovação tecnológica, exploração de novas fronteiras, novas fontes de energias, de outros povos, exploração crescente do trabalho, e que submete todas as metas e constantes transformações a essa perspectiva. Como também essa idealidade está embasada numa realidade material, isso significa uma busca permanente de aumento da produção, numa perspectiva que, movida pelo valor abstrato e indiferente do dinheiro, é igualmente abstrata e indiferente. O que, naturalmente, também significa certa indiferença em relação aos “recursos humanos" e à própria dimensão ecológica subjacente em suas particularidades, já que utilizados basicamente como meios para o fim central de multiplicação.

Finalmente, destacamos um último aspecto onde ideal e material se entrecruzam no capitalismo. Como já aludido por Godelier, os próprios agrupamentos que compõem uma relação de produção exigem diferenciações sociais que são forjadas e legitimadas a partir de representações ideais. Estas diferenciações podem ser feitas em diversas modalidades, e sempre ocorreram na história da humanidade. No capitalismo, ganham configurações particulares num contexto em que a diferenciação por classe foi destacada. Ela reflete a concentração dos meios de produção e a concomitante expropriação desses meios para uma grande maioria de indivíduos adultos (especialmente do sexo masculino, inicialmente, mas não apenas eles) instados cada vez mais a vender sua força de trabalho como única alternativa de sobrevivência.

Mas a própria condição dinâmica do capitalismo- movida pela idealidade da multiplicação permanente do valor - impede que as divisões sociais sejam fixas, embora, paradoxalmente, exija que elas sempre existam, como detalharemos em seguida. A própria separação étnica, como percebeu Wallerstein, pode ser usada para perfazer parte das divisões, mas mesmo ela tem de ganhar a maleabilidade necessária ao capitalismo, adaptando-se às exigências que esse modo de produção terá a cada momento.

Não devemos minimizar o grau até o qual a etnização da força de trabalho adiciona ao sistema capitalista um grau de flexibilidade que historicamente tem sido bem útil na manutenção de seu funcionamento eficiente. (...) É precisamente por ser tão incrivelmente maleável em suas manifestações específicas, embora definida ficticiamente como uma comunidade de realidades passadas imutáveis (...) que a 'etnicidade’ é tão difícil de apreender em termos de essências persistentes (2006, p. 105-106).

Nesse contexto, são várias idealidades que se atravessam na realização histórica de divisões sociais operadas pelo modo de produção capitalista, e elas podem ser reunidas como um modo particular e dinâmico de perfazer as divisões sociais - operado, de modo diferente, a cada estágio e local do capitalismo. O que podemos pensar aqui são algumas dimensões que ajudam a conjugar essas divisões. A primeira delas é a mais clássica, e não exigirá maiores detalhamentos: a própria concentração dos meios de produção acarreta uma grande divisão (embora com diversas nuances) entre capitalistas e trabalhadores. Foi nesse aspecto que Marx e Engels afirmaram (2014, p. 108) que "toda a sociedade divide-se mais e mais em dois grandes campos inimigos, em duas grandes classes, diretamente contrapostas - a burguesia e o proletariado".

Mas outras dimensões têm de ser pensadas. A ênfase quantitativa das relações de produção e troca exigiu, progressivamente, que as atividades a ela diretamente associadas, a produção de bens e serviços 
mercantilizáveis, fossem diferenciadas das outras atividades, igualmente cruciais, mas que não eram categorizadas como atividades produtoras de valor - atividades de subsistência, cuidar de uma casa, cuidar de crianças, idosos e doentes, atividades afetivas e sexuais. Reformulando uma categoria ressaltada por Marx (a da reprodução), diversas pensadoras feministas destacaram a importância dessas atividades e a separação promovida no capitalismo entre elas e as atividades de produção. Silvia Federici, por exemplo (2017, p. 100), fala da "separação entre produção e reprodução, trabalho remunerado e não remunerado, que nunca existiu em sociedades pré-capitalistas ou sociedades não reguladas pela lei do valor de troca”. Esta divisão, base essencial de um primeiro estágio de separação entre o ambiente doméstico, privado, e o ambiente semipúblico da produção, foi frequentemente uma divisão de gênero, com as mulheres em geral associadas às atividades de reprodução. O fato é que o modo de produção capitalista divide e separa, inclusive de modo valorativo, os grupos sociais dedicados a uma e outra atividade, mesmo que, dinamicamente, admita transformações nessa classificação?.

Os processos colonizatórios, por sua vez, impuseram outras exigências no âmbito de desenvolvimento da modernidade capitalista. Os povos colonizados, sejam os ameríndios, sejam os africanos, sejam os indianos ou asiáticos, sejam os descendentes desses povos, em diversas situações eram submetidos a atividades produtivas (e eventualmente reprodutivas) que eram diferenciadas das atividades dos europeus e seus descendentes. Frequentemente estas atividades eram desenvolvidas em contextos de servidão e/ou escravidão, e, mesmo quando essa condição era superada, a esses povos muitas vezes cabiam atividades menos qualificadas ou consideradas socialmente mais degradantes. Para que essa efetivação "material" fosse possível e legitimada, tornava-se necessária uma representação racial, com todo um arcabouço ideológico a ela associada. Foi isso o que percebeu o sociólogo Aníbal Quijano, ao forjar o conceito de colonialidade do poder, para ele central à própria compreensão da modernidade (capitalista), que exige, para desenvolver as suas várias modalidades de relações de produção, uma construção intersubjetiva (portanto, uma "idealidade") que as sustentem.

A estrutura colonial de poder produziu as discriminações sociais que posteriormente foram codificadas como "raciais", "étnicas", "antropológicas" ou "nacionais", segundo os momentos, os agentes e as populações implicadas. Essas construções intersubjetivas (...) foram inclusive assumidas como categorias (de pretensão "científica" e "objetiva") de significação ahistórica, ou seja, como fenômenos naturais e não da história do poder. Esta estrutura de poder foi e ainda é o marco dentro do qual operam as outras relações sociais, de tipo classista ou estamental (2006, p. 438).

Não se quer aqui encerrar as várias possibilidades de divisão social no capitalismo. O ponto a ressaltar é que categorias como classe, gênero e raça ${ }^{10}$, bem como a articulação entre elas, fazem parte do modo particular e dinâmico do capitalismo perfazer divisões sociais, como mecanismo para garantir as separações necessárias ao seu funcionamento, como a concentração dos meios de produção, a separação entre produção e reprodução, trabalho produtivo e trabalho doméstico, e mesmo a separação entre produção de maior valor e produção degradante. São separações como essas que dão sustentação a divisões sociais estabelecidas dinamicamente (sendo transformáveis, portanto) para mantê-las em alguma medida.

Assim, representações ideais do capitalismo como o individualismo, o nacionalismo, a primazia do

\footnotetext{
9 Nesse sentido, a crescente incorporação das mulheres no âmbito da produção não impede, dentro da dinâmica capitalista, que as atividades de reprodução sejam assumidas prioritariamente pelas mesmas mulheres (em dupla jornada), por outras mulheres, frequentemente a partir de uma marcação étnica, ou por outros grupos sociais.

10 Justamente as divisões ressaltadas por Angela Davis (2016) em seu pensamento e em sua militância.
} 
dinheiro e a multiplicação permanente do valor lidam, por sua vez, com o modo heterogêneo e insidioso com que este modo de produção atribui valores e papeis diferentes a diferentes grupos sociais, mesmo que isso seja flexibilizado e transformado sempre que necessário. Em países da periferia do sistema-mundo capitalista, como o Brasil, estas diferenciações ganham cores ainda mais vívidas, visto que a colonialidade do poder se impõe de maneira clara na subordinação de parte significativa da população negra e indígena, e de modo particular nas mulheres desses grupos sociais - com transformações históricas importantes, mas que não parecem lograr reverter o fundamento das diferenciações.

\section{A pandemia no capitalismo}

Com os elementos conceituais acima estabelecidos, podemos nos voltar para uma compreensão mais acurada do contexto da pandemia, e para alguns dos seus aspectos basilares. O primeiro ponto a ressaltar é que ela parece acentuar uma crise que já se anunciava historicamente no capitalismo. Não parece difícil compreender que o ideal da multiplicação permanente do valor seja inviável a longo prazo. Se o ser social está estruturado numa relação metabólica com a natureza - sua base ontológica ineludível -, e, no contexto capitalista, na exploração do trabalho humano, o seu crescimento constante significa justamente um desajuste dessa relação metabólica e uma tendência crescente de exploração. Isso provoca um crescimento constante da produção, mas também uma tendência a se alcançar limites cada vez mais inexpugnáveis desse crescimento, visto que não há espaço infinito para a exploração da natureza e do trabalho. Como afirmou Wallerstein (2006, p. 35), “à medida que aumenta, a mercadificação da terra, do trabalho e do capital caminham inexoravelmente para uma assíntota de cem por cento. Uma vez alcançados os níveis superiores dessa curva, cada passo adicional começa a impor uma compressão ao lucro global'". A tendência dessa fase aponta para uma competição cada vez mais selvagem por esses lucros, entre grupos sociais diferentes e entre povos diferentes.

Se essa competição já começava a apresentar aspectos dramáticos no Brasil ao menos desde 2014, quando o crescimento impulsionado na época do governo Lula começou a arrefecer, foi ganhando progressivamente repercussões políticas e sociais acentuadas, que exigiam um avanço mais forte nas medidas de exploração. Crescentemente, tivemos uma nova onda de pressões por "reformas" (redução do teto de gastos, reforma trabalhista, reforma da previdência) que retiravam prioritariamente das classes menos favorecidas recursos substanciais. No entanto, estas reformas não foram suficientes para o retorno ao tão desejado crescimento - crescimento de valor abstrato e da produção, em última instância.

O advento da pandemia acrescentava uma variável dramática a esse contexto, e reforçava uma contradição que já existia antes da sua chegada, mas agora numa curta escala temporal. Do ponto de vista meramente sanitário, algumas soluções eram basilares. A indiferenciação da produção em prol da abstração do dinheiro parecia perder a primazia para as soluções mais materiais e concretas exigidas: a prioridade na produção e distribuição de alimentos, bem como de alguns serviços básicos essenciais (particularmente na área de saúde), e um foco cada vez maior no aumento de leitos hospitalares, bem como equipamentos capazes de aparelhar o inevitável crescimento das populações hospitalizadas. Enquanto esse fortalecimento dos aparelhos de saúde não se efetivasse, medidas de isolamento social deveriam ser impostas, evitando uma rápida contaminação da população, especialmente aquela mais fragilizada, mas não só ela.

No entanto, essas priorizações, aparentemente tão racionais, enfrentam desafios no âmbito capitalista. A paralisação de diversas atividades não essenciais impõe, ao menos temporariamente, um colapso nas metas de crescimento. $\mathrm{O}$ mundo inteiro, tudo indica, passará por uma grande depressão econômica. 
Traduzindo: o mundo inteiro produzirá menos, quantitativamente, do que produzia nos anos anteriores, num contexto que já era de baixo crescimento médio mundial. No âmbito do capitalismo, isso significa: empregos podem ser ameaçados, a renda global pode cair.

É importante se compreender que esse não é um problema "natural" e inevitável. Se vivêssemos em um modo de produção sob o qual as relações não fossem basicamente mercantis e individualizadas, mas ainda baseadas em algum modelo de reciprocidade, a redução do crescimento não seria um problema absoluto. A questão mais importante seria como manter a produção de serviços considerados essenciais ${ }^{11}$ para o conjunto da população, independente do "crescimento" ou não da produção - decrescer poderia ser uma alternativa eventualmente aceitável, nesse caso, já que o mais importante seria a qualidade do que fosse produzido. A preocupação com “desemprego” também não seria tratada como tal, já que a própria busca por emprego se situa num âmbito de competição individualizada, num contexto em que os que "fracassam" os desempregados ou que só logram um trabalho degradante - supostamente "merecem" uma massa menor dos resultados da produção.

No modo de produção capitalista, obviamente, não é assim. A própria estruturação do individualismo sugere que há sempre vencedores ou perdedores. Por outro lado, os Estados, instituições por excelência das "comunidades inventadas" nacionais, mediam, parcialmente, certa selvageria absoluta da competitividade capitalista. É nesse sentido que criam, progressivamente, alternativas públicas de proteção aos mais vulneráveis, como sistemas públicos de saúde, sistemas de previdência, seguro-desemprego e outros mecanismos. No contexto da pandemia, outros dispositivos vão sendo criados: o Estado admite se endividar temporariamente para compensar as perdas salariais das empresas, aumentam os valores pagos à população vulnerável, fortalecem as redes de proteção à saúde, eventualmente relativizam a diferenciação entre sistemas públicos e mercantilistas de saúde com a publicização de leitos de saúde privados. E, acima de tudo, impõem medidas de isolamento social, que favorecem restrições temporárias ao crescimento econômico.

Naturalmente, estas medidas não significam, por parte dos Estados e seus agentes, uma abdicação dos princípios fundamentais (as "idealidades") do modo de produção capitalista. Elas representam um diferimento desses propósitos, seja porque um grande colapso do sistema de saúde também representa comprometimentos econômicos, seja porque, em alguma medida, os Estados assumem algum compromisso com os seus cidadãos, ao menos em questões tão definitivas quanto o risco de morte - nesse último caso, o modelo hobbesiano do Estado ao menos como protetor da vida e da segurança parece se impor.

Nesse ponto, surge outro fator e outra questão fundamental. A quem o Estado e seus agentes querem proteger fundamentalmente? A resposta "a seus cidadãos" parece um tanto vaga e abstrata. Como foi dito anteriormente, o capitalismo tem um modo particular e dinâmico de perfazer divisões de grupos sociais com diversas categorias (de gênero, raça, classe, entre outras) utilizadas para isso. Algumas dessas categorias tendem a receber a atribuição das tarefas de menor valor e/ou consideradas mais degradantes. Essa não é meramente uma desvalorização das atividades as quais desempenham esses indivíduos, mas em geral uma desvalorização dos próprios indivíduos que pertencem a determinado grupo social. Como se sabe, um mecanismo essencial para essa desvalorização foi a implícita ou explícita atribuição a parte desses indivíduos de um grau insuficiente de humanidade - considerada a humanidade uma idealidade de valor irretorquível, sobretudo na modernidade.

Aqui, é um momento em que o conceito de colonialidade do poder, de Aníbal Quijano, e o de necropolítica,

${ }^{11}$ A própria definição de "serviços essenciais" não é, naturalmente, um valor absoluto, ela também exige a formulação de "ideais" por um grupo social. 
de Achille Mbembe (2011), parecem se encontrar. Se Quijano demonstra que o padrão de poder mundial partiu da construção da ideia de raça, Mbembe mostra claramente que, no processo colonial, os direitos liberais não são assumidos plenamente, e isso está convenientemente associado ao próprio estatuto de humanidade dos colonizados. "A soberania significa ocupação, e a ocupação significa relegar os colonizados a uma terceira zona, entre o estatuto de sujeito e o de objeto" (2011, p. 43). Nesse contexto, "as colônias são o lugar por excelência no qual os controles e as garantias da ordem judicial são suspensos, onde a violência do estado de exceção supostamente opera a serviço da "civilização"' (2011, p. 39). Não é difícil associar essa noção colonial ao tratamento de comunidades em favelas brasileiras ou de povos indígenas em diversas regiões do país. Não é difícil, também, pensar em imigrantes em diversas partes do mundo "desenvolvido", sempre ameaçados, desde sua frágil condição jurídica, por um constante controle do Estado.

Estes são casos em que as clássicas diferenciações de classe não parecem ser suficientes. A heterogeneidade da colonialidade do poder sugere também uma ampla faixa hierárquica no estatuto de humanidade que afeta a sensibilidade e as políticas do Estado e da própria opinião pública em relação aos povos afetados. Ao mesmo tempo, eles são justamente os grupos com maior risco de morte no contexto da pandemia, por diversas razões - piores condições sanitárias, saúde mais fragilizada, maior densidade populacional, menor capacidade de isolamento dos idosos, menor disponibilidade financeira para o isolamento social, menor acesso ao sistema de saúde, entre outros fatores. Em países como Brasil e Estados Unidos, essa diferenciação nos índices de mortalidade dos mais vulneráveis já é patente.

Justamente nesses países, o número de "negacionistas" parece ser maior. Especialmente entre os empresários e a classe média mais privilegiada, pulularam manifestações reivindicando a "volta à normalidade" - no caso brasileiro, com o slogan "o Brasil não pode parar". Não pode parar de produzir bens e serviços de toda ordem, entenda-se. $\mathrm{O}$ fato de que foram comuns manifestações em carros, apresentando baixo risco para os manifestantes, tornava tudo mais emblemático. O fato de que eram manifestantes certamente com planos de saúde privados, com maior disponibilidade de leitos hospitalares por indivíduo, também.

A associação desses grupos ao termo negacionismo é emblemática. Como mostraram os pesquisadores Pascal Diethelm e Martin Mckee, num pequeno mas influente artigo (2009), embora esse termo tenha surgido dos negacionistas históricos (como no caso do holocausto), ele foi reutilizado para casos bem sintomáticos, como a negação do risco de morte no uso do tabaco (inclusive para os fumantes passivos) e do papel humano nas mudanças climáticas. Em ambos os casos, uma negação com forte apoio das indústrias tabagista e do petróleo, com óbvios interesses associados, acompanhada de uma construção sistemática de falácias, recrutamento de "falsos especialistas" e campanhas contra pesquisadores independentes. Nesses casos, as idealidades da primazia do dinheiro e da multiplicação permanente do valor não pareciam admitir oposição. O negacionismo significava uma espécie de apelo capitalista: "a produção não pode parar".

No caso da pandemia da Covid-19, essa componente traz um agravante. Como há uma clara desigualdade na população afetada, embora todos o sejam de algum modo, o negacionismo parece ganhar um reforço estruturado na própria colonialidade do poder, o que justifica o seu reforço em países com mais divisões sociais "étnicas". A ponto do presidente de uma grande corretora de valores ter dito em pleno crescimento dos mortos: "eu diria que o Brasil está bem. (...) O pico da doença já passou quando a gente analisa a classe média, classe média alta. O desafio é que o Brasil é um país com muita comunidade, muita favela". ${ }^{12}$

12 Conforme reportagem na Folha de São Paulo em 05/05/2020, obtida no link https://www1.folha.uol.com.br/merca 
Não se visa aqui qualquer condenação a uma manifestação individual, por mais chocante que ela possa parecer. O modo de produção capitalista, e a divisão social que ele enseja, articula suas exigências "ideais" cada vez mais profundamente, afetando (de diversas maneiras) a sensibilidade e os valores de cada um dos participantes dessa relação social. É exatamente porque esses mecanismos materiais e ideais são tão imbricados que a sua transformação se torna tão complexa, ganhando, em alguns momentos, aparência de irreversibilidade.

\section{Há uma reversão possível?}

A partir da referência da Covid-19 e seus desdobramentos, a investigação aqui propugnada buscou analisar a profunda imbricação entre material e ideal na própria condição humana, e mais especificamente no modo de produção capitalista. Nessa investigação, mostrou que as próprias idealidades forjadas no âmbito desse modo de produção direcionam para certas práticas materiais específicas e certos modos de diferenciação social, em diversos aspectos contraditórios - num ideal inalcançável de expansão permanente, numa indiferença qualitativa em relação ao que se produz e o que nos é, de fato, essencial, e em discriminações sociais que praticamente negam o estatuto de plena humanidade a uma parcela da população. A aparente irracionalidade de certa busca negacionista da "volta à normalidade" só explicita isso.

Há uma reversão possível a essa irracionalidade? Como o capitalismo é um modo de produção constituído historicamente, a pergunta só pode ser respondida com uma sonora resposta positiva. Mais que isso: qualquer análise detida sobre o seu significado só pode concluir que o modelo de auto-expansão do capitalismo é inexequível a longo prazo. A questão é imaginar se a sua reversão se dará em prol de algo melhor para a humanidade, de alguma espécie de tirania ou se caminhamos para uma inviabilização da própria existência humana no planeta - os aspectos ambientais vinculados à pandemia seriam apenas um dos sintomas dessa última possibilidade.

Apesar disso, a estranha sensação de certa eternidade e "naturalidade" do capitalismo se deve justamente ao fato de que as "idealidades" que o acompanham, o individualismo, o nacionalismo, a primazia do dinheiro, o ideal de multiplicação permanente do valor e as segmentações sociais que o servem, serem idealidades que se encarnam, que afetam de modo profundo mesmo os seus mais empedernidos adversários. O que impõe o paradoxo que Marx já percebera nas Teses sobre Feuerbach (1998, p. 100) ao lembrar que "o próprio educador precisa ser educado" e que não faz sentido "dividir a sociedade em duas partes, uma das quais está acima da sociedade".

Esta constatação de Marx já exclui algumas falsas soluções. Certamente, qualquer processo de reversão não parte de mera "conscientização" que nos torne menos individualistas, menos apegados à primazia do dinheiro, menos discriminatórios etc., solução que seria basicamente idealista. Do outro lado, dificilmente está numa transformação "material" abstrata assumida por um grupo de vanguarda "acima da sociedade" que imponha autoritariamente a mudança do modo de produção e, quem sabe, alguma "revolução cultural" - afinal, as "idealidades" não se modificam por decreto.

A imbricação entre material e ideal (a práxis, afinal; como tal, uma ação coletiva e social) exige um desmantelamento prático cada vez mais sistemático das formas capitalistas de viver, das segmentações individualistas que elas ensejam, experimentando e colocando no lugar outras possibilidades, frequentemente 
precárias e falhas como toda experiência humana, nos diversos âmbitos (local, regional, "nacional” e planetário), no contexto de uma luta cada vez mais necessária pela superação do capitalismo e pela descoberta de formas criativas e comunitárias de se viver. Tudo indica que é isso ou a barbárie, como já notara Rosa Luxemburgo (LOUREIRO, 2009). Os conflitos resultantes da pandemia, ao menos no Brasil, parecem revelar essa disjuntiva de forma assustadoramente clara.

\section{REFERÊNCIAS}

COHEN, Gerald. La teoria de la historia de Karl Marx: uma defensa. Tradução de Pilar López Máñez. Madrid: Pablo Iglesias, 1986.

COSSUTTA, Frédéric. Elementos para a leitura dos textos filosóficos. Tradução de Angela de Noronha Begnami et al. São Paulo, Martins Fontes, 1994.

DAVIS, Angela. Mulheres, raça e classe. Tradução de Heci Regina Candiani. São Paulo: Boitempo, 2016.

DIETHELM, Pascal e MCKEE, Martin. "Denialism: what is it and how should scientists respond?". European Journal of Publich Health, 19, 2-4.

FEDERICI, Silvia. “Notas sobre gênero em O Capital de Marx”. Tradução de Giovanna Henrique Marcelino. Cadernos cemarx, 10, 83-111.

GODELIER, Maurice. Lo ideal y lo material: pensamiento, economias, sociedades. Tradução de A. J. Desmont. Madrid: Taurus Humanidades, 1989.

LOUREIRO, Isabel (Org.). Socialismo ou barbárie: Rosa Luxemburgo no Brasil.

LUKÁCS, Györg. Para uma ontologia do ser social. Tradução de Nélio Schneider, Ivo Tonet e Ronaldo Vielmi Fortes. São Paulo: Boitempo, 2013. $2^{a}$ edição. São Paulo: Estação das Artes, 2009.

MARX, Karl e ENGELS, Friedrich. A ideologia alemã. Tradução de Luís Cláudio de Castro e Costa. São Paulo: Martins Fontes, 1998.

MARX, Karl. e ENGELS, Friedrich. Manifesto do partido comunista. Tradução de Luciano Cavini Martorano. São Paulo: Martin Claret, 2014.

MARX, Karl. O capital: crítica da economia política, volume 1, livro primeiro. O processo de produção do capital. Tomo 1. Tradução de Regis Barbosa e Flávio Kothe. São Paulo: Nova Cultural, 1996.

MARX, Karl. “Teses sobre Feuerbach”. In: MARX, Karl e ENGELS, Friedrich. A ideologia alemã. Tradução de Luís Cláudio de Castro e Costa. São Paulo: Martins Fontes, 1998.

MARX, Karl. Contribuição à crítica da economia política. $2^{\mathrm{a}}$ Ed. Tradução de Florestan Fernandes. São Paulo: Expressão Popular, 2008.

MARX, Karl. Manuscritos econômico-filosóficos. Tradução de Jesus Ranieri. São Paulo: Boitempo, 2010.

MARX, Karl. Grundrisse: manuscritos econômicos de 1857-1888: esboços da crítica da economia política. Tradução de Mário Duayer e Nélio Schneider. São Paulo: Boitempo; Rio de Janeiro: Ed. da UFRJ, 2011.

MAUSS, Marcel. "Ensaio sobre a dádiva. Forma e razão da troca nas sociedades arcaicas". In: MAUSS, Marcel. Sociologia e antropologia. Volume II. Tradução de Mauro de Almeida. São Paulo: EPU, 1974. 
MBEMBE, Achille. Necropolítica. Seguido de Sobre el gobierno privado indirecto. Tradução de Elisabeth Falomir Archambault. Madrid: Melusina, 2011.

QUIJANO, Aníbal. "Colonialidade e modernidade-racionalidade”. In: BONILLA, Heraclio (Org.). Os conquistados: 1492 e a população indígena das Américas. Tradução de Magda Lopes. São Paulo: Hucitec, 2006.

SOMBRA, Laurenio Leite. "Identidade dos sujeitos: linguagem, constituição de sentido e valor". Revista Sísifo, 1, 2015, p. 95-114.

SOMBRA, Laurenio Leite. "Entre o discurso e a ontologia do ser social: possibilidades de um debate”. Revista Ideação: 39, 2019, p. 111-129.

TEMPLE, Dominique. La dialectica del don: ensayo sobre la oikonomía de las comunidades indígenas. Tradução de Maria Rosa Montes. La Paz: Hisbol, 1995.

TEMPLE, Dominique. Teoría de la reciprocidad, tomo I: la reciprocidad y el nacimiento de los valores humanos. Tradução de Juan Cristobal MacLean. La Paz: Padeb e GTZ, 2003.A pandemia o ideal e o material

THOMPSON, Edward. “Folclore, antropologia e história social”. Tradução de Antonio Luigi Negro. In: NOVAES, Adauto (Org.). A outra margem do Ocidente. São Paulo: Companhia das Letras, 1999.

VILLORO, Luís. Estado plural, pluralidad de culturas. México: UNAM/Paidós, 1998.

WALLERSTEIN, Immanuel. Capitalismo histórico e civilização capitalista. Tradução de Renato Aguiar. Rio de Janeiro: Contraponto, 2001.

WALLERSTEIN, Immanuel. Impensar a ciência social: os limites dos paradigmas do século XIX. Tradução de Adail Sobral e Maria Stela Gonçalves. Aparecida-SP: Ideias \& Letras, 2006.

Artigo recebido em: 30 de maio de 2020

Artigo aceito em: 25 de junho de 2020 